\title{
Characterization of an Egyptian Spodoptera littoralis nucleopolyhedrovirus and a possible use of a highly conserved region from polyhedrin gene for nucleopolyhedrovirus detection
} AlaaEddeen M Seufi

Address: Department of Entomology, Faculty of Science, Cairo University, Giza, 12211, Egypt

Email: AlaaEddeen M Seufi - alaaseufi@yahoo.com

Published: 23 january 2008

Virology Journal 2008, 5:13 doi:10.1186/1743-422X-5-13

This article is available from: http://www.virologyj.com/content/5/I//3

(c) 2008 Seufi; licensee BioMed Central Ltd.

This is an Open Access article distributed under the terms of the Creative Commons Attribution License (http://creativecommons.org/licenses/by/2.0), which permits unrestricted use, distribution, and reproduction in any medium, provided the original work is properly cited.
Received: 18 October 2007

Accepted: 23 January 2008

\begin{abstract}
An Egyptian isolate of Spodoptera littoralis nucleopolyhedrovirus (SpliNPV) was tested for its potential as biocontrol agent in comparison to Autographa californica multiple nucleopolyhedrovirus (AcMNPV). Comparative assays of SpliNPV and AcMNPV against $2^{\text {nd }}$ instar larvae of Spodoptera littoralis revealed 4-fold greater susceptibility of $S$. littoralis to AcMNPV than to SpliNPV based on $\mathrm{LC}_{50}$ values for the two viruses. The $\mathrm{LT}_{50} \mathrm{~s}$ determined for SpliNPV and AcMNPV using $\mathrm{LC}_{50}$ of the virus against $2^{\text {nd }}$ instar larvae were 4.2 and 5.8 days, respectively. A DNA segment of 405 bp containing highly conserved region from polyhedrin gene of SpliNPV (Polh-cr) was successfully amplified by PCR. Subsequently, this DNA segment was cloned and sequenced. Nucleotide sequence and its deduced amino acid sequence were compared to all available sequences in GenBank. Sequence alignment results revealed that Polh-cr showed significant similarities with 9| different baculovirus isolates. The percentage of homology ranged from $78 \%$ for Plusia orichalcea NPV to $99 \%$ for SpliNPV. This highly conserved region provides a candidate that could be used in easy, fast and economic prospective systems for virus detection as well as in biological control strategies.
\end{abstract}

\section{Introduction}

Baculoviruses are considered to be the largest and most broadly studied insect viruses. Although they infect over 600 species of insects [1], individual isolates normally show a limited host range and infect only closely related species. It is believed that baculoviruses are potentially useful as safe biological control agent and in some cases they were used successfully to control different insect pests [2-4]. However the overall use of baculoviruses for biological control is limited compared to other pest control means $[3,5]$. This is due to the virulence and speed of action, as related to dose, host range, cost of production and patent registration are important effectiveness-determining properties of insect-pathogenic biocontrol agents.
Baculoviruses were not only isolated from the insect orders Hymenoptera, Diptera and Trichoptera, but also were isolated from the crustacean order Decapoda (shrimps) [6]. Furthermore, some NPVs (Penaeus monodon-NPV) are considered as serious pests for marine crustaceans [7]. The infection of marine crustaceans (shrimps, prawns, crabs, eustacosa...etc.) with NPV will reduce their economic value and thus negatively affecting the national income. This problem will arise in countries that depend on marine wealth as a source of national income and/or where marine crustaceans are a major in most of the peoples' food (Australia and Far East nations like Japan, China, etc...). Although, the shrimp viruses have now been classified as Nimaviridae in the genus Whispovi- 
rus and are no longer baculoviruses [8], their diagnosis by PCR using primers of the polyhedrin and DNA polymerase genes of Autographa californica nucleopolyhedrovirus (AcMNPV) and Lymantria dispar nucleopolyhedrovirus (LdMNPV) was confirmed by Hsu et al. (2000). For the above mentioned reasons, many authors were interested in developing an accurate and easy diagnostic method to detect baculoviral infection in larval shrimps as well as insects $[9-13,7,14-19]$.

Because baculoviruses are of great interest and utility to a large cross-sections of agricultural and biomedical research community, selection of some isolates with natural improved characteristics and definitive characterization of them have appeared recently. Consequently this piece of work will help in viral epidemiology, in monitoring the viral dissemination after field application and in risk assessment studies.

Therefore, the main objective of the present work is to obtain a sequenced highly conserved DNA fragment from our NPV isolate to be used in an easy, fast and economic prospective system for virus detection. Also, this DNA segment can be used for developing kits of ELISA, hybridization, Western and dot blotting. Furthermore, our NPV isolate may be useful as potential biocontrol agent in programs of integrated pest management (IPM).

\section{Methods \\ Insects}

Laboratory colony of the cotton leaf worm, Spodoptera littoralis, was originally collected from Giza, Egypt and maintained in the insectary of Agricultural Genetic Engineering Research Institute (AGERI) under highly controlled conditions from 1990 to date. The colony was maintained in the laboratory according to the technique described by El-Defrawi and coworkers [20]. Larvae were reared on a semisynthetic diet described by Levinson and Navon [21]. This colony was kept at $25 \pm 2{ }^{\circ} \mathrm{C}, 65-70 \%$ $\mathrm{RH}$ and natural photoperiod. These insects were used for viral propagation and bioassays.

\section{Viruses}

An NPV isolate was selected from thirteen Egyptian baculovirus isolates from different geographical localities during 1996-2000. This isolate was studied in detail to determine its insecticidal activity compared to AcMNPV. In addition, a highly conserved region of polyhedrin gene was amplified, cloned and sequenced for further investigations. The selected isolate was collected from an Egyptian field located at Khorshid, Alexandria. It was isolated during Jan, 1999 from a S. littoralis larva on cabbage plants. This isolate was successfully propagated, purified following the method described by Lacey and coworkers [22] and used for further studies.
A virus stock of NPV from Autographa californica nuclear polyhedrosis virus (AcMNPV; $\mathrm{E}_{2}$ strain) was originally obtained from Prof. Dr. Suzanne Thiem, Department of Entomology, University of Michigan, was used in the bioassays as a reference in comparison to our isolate.

\section{Insecticidal activity}

Laboratory bioassay tests were conducted using highly purified virus suspensions. The SpliNPV and AcMNPV isolates were tested against $2^{\text {nd }}$ larval instar from the virusfree rearing culture in the laboratory. The concentrations were measured using Thoma haemocytometer and light microscope [22]. Bioassays were performed using five concentrations of each virus isolate. Tested larvae were starved for 8 hours prior to feeding viruses. Serial dilutions of each tested isolate were prepared beginning with the following stock concentrations in PIB/ml: $7.8 \times 10^{4}$ and $9.4 \times 10^{4}$ for SpliNPV and AcMNPV, respectively. Bioassays were carried out in plastic cups measuring $15 \mathrm{~cm}$ diameter $\times 10 \mathrm{~cm}$ height and containing a layer of $1 \mathrm{~cm}$ semi-synthetic diet. The viral suspensions were dispersed on the diet using micropipette ( $25 \mu \mathrm{l}$ suspension/larva). Forty larvae were used for each concentration of virus and control. The control larvae were fed on diet treated with distilled water. All treatments were kept at $25 \pm 2{ }^{\circ} \mathrm{C}$ and normal photoperiod. The experiment was replicated thrice for each virus isolate and control. Mortality was recorded on the $7^{\text {th }}$ day post-infection then corrected according to Abbott's formula [23]. Cumulative mortality was recorded daily and the experiment was stopped on day 10 post-infection. Mortality was corrected according to Abbott's formula [23].

\section{Statistical analyses}

Probit analysis of mortality data from bioassays was conducted using SPSS (ver10.0) computer software (SPSS for Windows, SPSS Inc., 1997). The LT values for the tested isolates were derived from analysis of data on the progression of mortality of $S$. littoralis larvae, following exposure to the $\mathrm{LC}_{50} \mathrm{~s}$ dosage using probit analysis modified for multiple observations over time [24] and Mathematica software (Wolfram, Champaign, IL).

\section{PCR amplification}

PCR amplification was performed according to Saiki and coworkers [25] with minor modifications. Total DNA was extracted from the NPV isolate and the DNA segment was amplified using two primers designed based on conserved nucleotide sequences of ten different polyhedrin genes [26]. The forward primer: GG(GT) CC(GT) GGC AAG AAT CAG AA and the reverse one: GCG TC(TG) GG(TG) GCG AAC TCT TT(TG) ATT TT. Total reaction volume was $50 \mu \mathrm{l}$ which contained $1 \times$ PCR buffer (Promega), $1.5 \mathrm{mM}$ $\mathrm{MgCl}_{2}, 200 \mu \mathrm{M}$ dNTPs, $2.5 \mathrm{U}$ Taq DNA polymerase (Promega), $100 \mathrm{ng}$ of each primer and $30 \mathrm{ng}$ of template 
DNA. The amplification program used was $3 \mathrm{~min}$ at $94^{\circ} \mathrm{C}$ (hot start), $1 \mathrm{~min}$ at $94^{\circ} \mathrm{C}, 2 \mathrm{~min}$ at $55^{\circ} \mathrm{C}$ and $2 \mathrm{~min}$ at $72^{\circ} \mathrm{C}$ for 35 cycles followed by one cycle of $72^{\circ} \mathrm{C}$ for 7 min. PCR amplification was carried out in a DNA thermal cycler (Model 380 A, Applied Biosystems, CA, USA).

\section{Cloning of a highly conserved region from SpliNPV polyhedrin gene}

The positive PCR products were visualized and eluted from the gel using GenClean Kit (Invitrogen Corporation, San Diego, CA, USA) as described by the manufacturer. The purified PCR products and a $p$ GEM-T vector (Promega Corporation, Madison, WI, USA) were mixed in a 5: 1 (insert: vector) molar ratio and ligated using $\mathrm{T}_{4} \mathrm{DNA}$ ligase (as described by the manufacturer). Ligation mix was used to transform competent Escherichia coli $\mathrm{JM}_{109}$ cells (Stratagene, La Jolla, CA, USA). White colonies were screened using PCR as described earlier in this section.

\section{Nucleotide sequence and sequence analysis}

Only one clone $p G N P V-95$ was selected and sequenced using $\mathrm{M}_{13}$ universal forward and reverse primers. Sequencing was performed using $\mathrm{T}^{7}$ Sequencing $\mathrm{T}^{\mathrm{M}}$ kit (Pharmacia, Biotech) and model 310 automated sequencer (Applied Biosystems, Foster City, CA, USA). Analysis of nucleotide and deduced amino acid sequences was carried out using EditSeq-DNAstar Inc., Expert Sequence Analysis software, Windows 32 Edit Seq 4.00 (1989-1999) and ExPasy database on the internet. Blast search for alignment of the obtained sequence with the published ones was done using database of National Centre for Biotechnology Information (NCBI). The cloned DNA fragment (Polh-cr) was deposited in GenBank under the AY442260 accession number.

\section{Results}

\section{Field survey}

During the present study, the most promising isolate, as a biocontrol agent (based on LC and LT values), was selected from thirteen Egyptian baculovirus isolates. Through four visits to the location, out of 63 collected $S$. littoralis larvae, 18 larvae were diseased (showed symptoms of viral infection). The virus was diagnosed using light microscope, propagated in a $S$. littoralis laboratory colony, purified and kept at $-80^{\circ} \mathrm{C}$ for further studies.

\section{Insecticidal activity}

Table (1) presents the LC and LT values for the two tested isolates (SpliNPV and AcMNPV). It is clear that the newly molted $2^{\text {nd }}$ larval instars of $S$. littoralis were susceptible to the applied concentrations. Based on $\mathrm{LC}_{50}$ in $\mathrm{PIB} / \mathrm{ml}$, our SpliNPV isolate was significantly (4-fold) less active ( $\mathrm{LC}_{50}$ $\left.=1.2 \times 10^{3}\right)$ than the reference strain AcMNPV $\left(\mathrm{LC}_{50}=3.7\right.$ $\times 10^{2}$ ). Although $\mathrm{LC}_{25}$ and $\mathrm{LC}_{95}$ of our isolate were approximately 2 and 8 -fold lower than that of AcMNPV, there were substantial overlap in the $95 \%$ confidence limits of the two viruses. Time to death showed some dependence on the initial concentration. Furthermore, it was observed that the highest peak of mortality was on 4-6 days post-infection. The progression of mortality in $2^{\text {nd }}$ instar larvae of $S$. littoralis over a 10-day-period following exposure to $\mathrm{LC}_{50}$ dosage of the two viruses was analyzed to produce LT values (Table 1). Probit analysis of the LT values revealed that the decrease in LT values in favour of our isolate against $A c \mathrm{MNPV}$ was not significant. Despite the overlap in the $95 \%$ confidence intervals of the two viruses, $\mathrm{LT}_{95}$ of our isolate was nearly 4 days less than that of AcMNPV (95\% c.i. 9.7-25.4 days, $X^{2}=2.64, \mathrm{DF}=8, \mathrm{P}$ $=0.96$, slope $=3.49 \pm 0.74)$.

\section{PCR amplification}

Two oligonucleotide primers were designed to amplify 537 bp within the open reading frame (orf) of polyhedrin gene [26] and were successfully used in PCR. PCR analysis of our results revealed that a DNA fragment of only 405 bp was amplified within the orf (beginning about $78-81$ codons after the starting codon, AUG) of the SpliNPV-95 polyhedrin gene (Fig. 1, lane 5). Subsequently this DNA segment was cloned into pGEM-T vector (Fig. 1, lane 2) and transformed cells were tested with PCR using the same primers (Fig. 1, lane 6). Using this screening method, clone pGNPV-95 was tested as positive (Fig. 1, lane 6).

Table I: Susceptibility of 2 nd instar larvae of $S$. littoralis to the nucleopolyhedroviruses of $A$. californica (AcMNPV) and S. littoralis (SpliNPV)

\begin{tabular}{|c|c|c|c|c|c|c|}
\hline \multirow[t]{2}{*}{ Isolate } & \multicolumn{3}{|c|}{ LC values in PIB/ml (95\% confidence limits) } & \multicolumn{3}{|c|}{ LT values in days ( $95 \%$ confidence limits) } \\
\hline & $\mathbf{L C}_{25}$ & $\mathbf{L C}_{50} *$ & $\mathbf{L C}_{95}$ & $\mathbf{L} \mathbf{T}_{25}$ & $\mathbf{L T}_{50}$ & $\mathbf{L T}_{95}$ \\
\hline AcMNPV & $\begin{array}{c}19.5 \\
(4.8-4.0 \times 10)\end{array}$ & $\begin{array}{c}3.7 \times 10^{2} \\
\left(1.9 \times 10^{2}-6.7 \times 10^{2}\right)\end{array}$ & $\begin{array}{cl} & 7.5 \times 10^{5} \\
\left.2.4 \times 10^{5}-3.7 \times 10^{6}\right)\end{array}$ & $\begin{array}{c}3.7 \\
(2.50-4.59)\end{array}$ & $\begin{array}{c}5.8 \\
(4.73-7.14)\end{array}$ & $\begin{array}{c}17.2 \\
(12.01-39.03)\end{array}$ \\
\hline SpliNPV & $\begin{array}{c}39.3 \\
(1.4 \times 10-8.2 \times 10)\end{array}$ & $\begin{array}{c}1.2 \times 10^{3} \\
\left(6.9 \times 10^{2}-2.3 \times 10^{3}\right)\end{array}$ & $\begin{array}{c}6.1 \times 10^{6} \\
\left(4.5 \times 10^{5}-1.9 \times 10^{7}\right)\end{array}$ & $\begin{array}{c}2.6 \\
(1.65-3.39)\end{array}$ & $\begin{array}{c}4.2 \\
(3.26-5.17)\end{array}$ & $\begin{array}{c}13.4 \\
(9.74-25.42)\end{array}$ \\
\hline
\end{tabular}

Significant difference at $95 \%$ confidence interval 


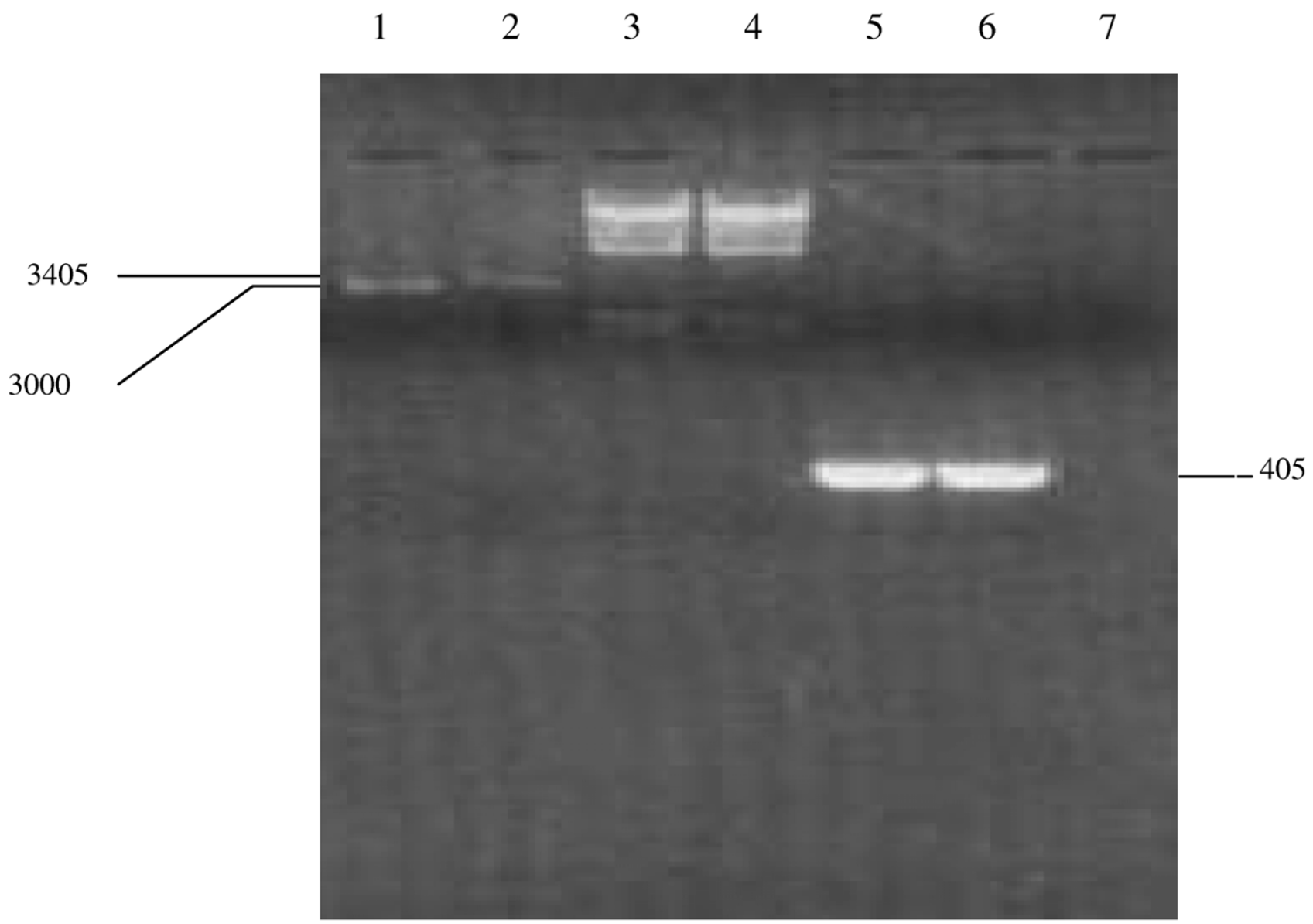

\section{Figure I}

Agarose gel electrophoresis showing clone pGNPV-95 after linearization with Ndel, and PCR confirmation. Lanes I and 2 show pGEM-T and pGNPV-95 after digestion with Ndel, respectively. Lanes 3 and 4 show Lambda DNA/HindIII Marker. Lanes 5, 6 and 7 show the 405 bp amplified DNA segment from SpliNPV (as positive control), from E. coli harbouring pGNPV-95 and PCR mix without DNA (as negative control), respectively. The size of the bands is shown in bp.

\section{Nucleotide sequence and sequence analyses}

The nucleotide sequence of Polh-cr and its deduced amino acid sequence are shown in Fig (2). A single open reading frame (orf) that could encode a polypeptide of 135 amino acids was detected. No stop codon was found all over the sequence. This deduced polypeptide contains 16 strongly basic, 16 strongly acidic, 46 hydrophobic and 34 polar amino acids. The calculated molecular mass of the putative polypeptide is $15.92 \mathrm{KDa}$. Isoelectric point (PI) is 7.242 and the charge at $\mathrm{pH} 7.0$ is 0.331 .

The nucleotide sequence of Polh-cr was blasted in GenBank database and compared to all available sequences. Alignment results revealed that Polh-cr has significant alignment with 111 baculovirus isolates (100 NPVs and 11 GVs). The percentage of homology ranged between $99 \%$ for SpliNPV (Acc\# D01017) and 78\% for Plusia orichalcea NPV (Acc\# AF019882). Interestingly Polh-cr produced significant alignments with 11 granulovirus sequences. This may raise the question of possible homologous recombination between NPV and GV species.

Comparing Polh-cr nucleotide sequence (Acc\# AY442260) to its corresponding sequence of AcMNPV (Acc\# M25054) as a reference, $82 \%$ homology, 57 different nucleotides and 12 gaps were observed throughout the compared DNA segments (Fig 3).

The deduced amino acid sequence was compared to all other polyhedrins in GenBank database. Alignment results showed that the percentage of homology of Polh-cr ranged between $100 \%$ for S. littoralis polyhedrins (Acc\# AAC33752 and AAR04375) and 81\% for Attacus ricini polyhedrin (Acc\# P31036). 


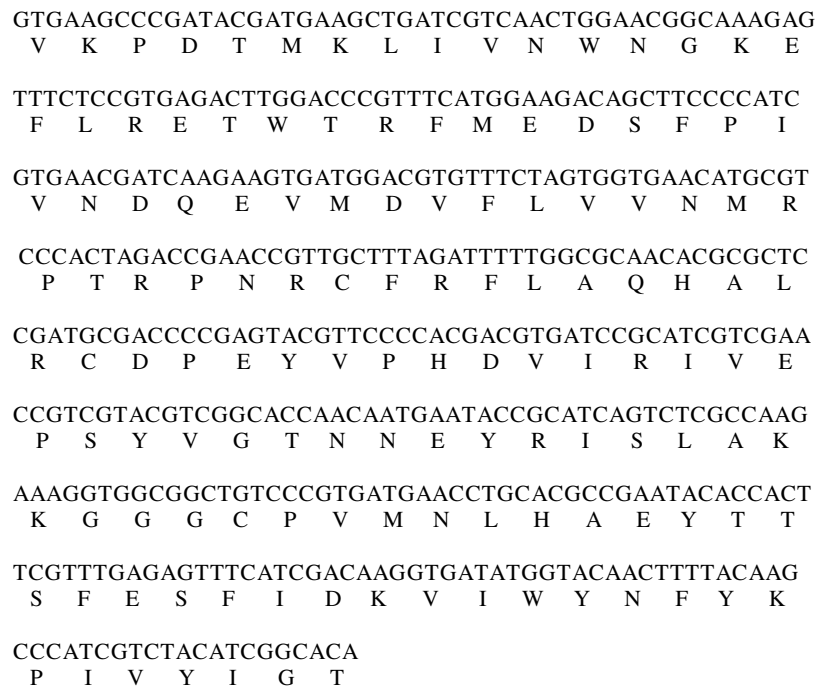

\section{Figure 2}

Nucleotide and corresponding deduced amino acid sequence of a highly conserved region of polyhedrin gene (polh-cr).

On comparing amino acid sequence of the putative polypeptide of Polh-cr (Acc\# AAR04375) to its corresponding sequences of AcMNPV (Acc\# $\underline{\text { AAA46736) }}$ ) and other 4 SpliNPVs (Acc\# $\underline{\text { AAW49208, BAA00824, }}$ AAT10182 and AAW49207), 15 different amino acids were observed throughout the compared putative polypeptides using AcMNPV as a reference (Fig. 4). It is note worthy to mention that all SpliNPVs amino acid sequences (Acc\# AAW49208, BAA00824, $\underline{\text { AAT10182 and }}$ AAW49207) were identical to Polh-cr putative polypeptide (Acc\# AAR04375) except for the position 133 (I a.a. was replaced with $\mathrm{V}$ a.a.).

\section{Phylogenetic analyses of Polh-cr}

Phylogenetic analyses have been performed on the Polh-cr nucleotide seuquence and its deduced polypeptide and results of these analyses are shown in Figs. (5 and 6). In case of Polh-cr nucleotide seuquence, a phylogenetic tree was generated from sequence data of 38 NPV isolates by neighbor-joining distance analysis with maximum sequence difference 0.75 (Fig. 5). The topology shows four distinct lineages including 5, 21, 8 and 4 NPV isolates, respectively. The maximum nucleotide sequence divergence was exhibited in lineage II. Meanwhile, the NPV isolates appear in the other three lineages as monophyletic sister clades (Fig. 5). In case of Polh-cr deduced amino acid seuquence, a phylogenetic tree was generated from sequence data of 102 NPV isolates by neighbor-joining distance analysis with maximum sequence difference 0.75 (Fig. 6). The topology shows three distinct lineages including 17, 60 and 25 NPV isolates, respectively. The maximum divergence of amino acid sequences was exhib- ited in lineage II. However, minimum divergence in case of the other two lineages was observed. Otherwise, polyhedrins from many NPV isolates appear in monophyletic sister clades (Fig. 6).

\section{Discussion}

To date, genetically engineered baculoviruses introduce a promising research line to overcome the slow action of baculoviruses as biocontrol agents. On the other hand, searching for new natural baculovirus isolates with better insecticidal characteristics is still a developing subject of work (more safe and has not the risks of releasing genetically engineered product in nature). Although AcMNPV is considered as the type species in the genus nucleopolyhedrovirus, 15 species and 471 tentative species of NPV have been isolated [27]. Abul-Nasr [28] isolated an Egyptian NPV from the cotton leaf worm S. littoralis. Cherry and Summers [29] isolated the two reference NPV types A and B. During 1986 - 1988, six natural isolates of SpliNPV were isolated from Giza, Menya, Kaha, Tokh, KafrElsheikh and Gharbyia, Egypt (Khamiss, personal communication). Also, fifteen isolates of SpliNPV were isolated from the six above mentioned Egyptian localities in addition to Fayoum, Sakkara, Menofyia, Benisuef, Asyut, Sinnuris, Banha, Sharkyia and Elsaff-Giza, Egypt (Khamiss, personal communication).

Combining our data with that presented by Khamiss and by Seufi (personal communication), it can be concluded that 34 NPV isolates have been collected from Egypt between 1986 and 2000. This may reflect the suitability of the Egyptian environment for not only gathering and collecting new baculovirus isolates but also for using them as potential pesticides in integrated pest management (IPM) programs. Given that baculoviruses have been isolated from Upper as well as Lower Egypt, in which the cultivation was washed by chemical insecticides, it would be expected to find more and more isolates in virgin regions (where no insecticides were used).

The susceptibility of $2^{\text {nd }}$ instar larvae of $S$. littoralis to the two polyhedrovirus species reported in this study was comparable to that observed by Lacey and coworkers [22]. They reported that $\mathrm{LC}_{50} \mathrm{~s}$ were $1.77 \times 10^{3}$ and $3.05 \times 10^{3}$ occlusion bodies (OB) $/ \mathrm{mm}^{2}$ for Anagrapha falcifera (AfMNPV) and Autographa californica (AcMNPV) when applied to the neonate codling moth larvae. Our Egyptian isolate (SpliNPV) showed similar results to that obtained by Klein and Podoler against the Egyptian cotton leafworm [30]. Abot and coworkers [31] clarified that $\mathrm{LC}_{50} \mathrm{~s}$ of an NPV isolate against two A. gemmatalis populations varied from 129 to $316 \mathrm{OBs} / \mathrm{ml}$ diet. Their results fall within the range obtained with our isolate. On the other hand, our results showed lower $\mathrm{LC}_{50}$ when compared with that reported by Pawar and Ramakrishnan [32] and Komolp- 


\begin{tabular}{|c|c|c|c|}
\hline SpliNPV & 4 & AAGCCCGATACGATGAAGCTGATCGTCAACTGGAACGGCAAAGAGTTTCTCCGTGAGACT & 63 \\
\hline ACMNPV & 1484 & ACACCATGAAGCTGGTAGTAAACTGGAGCGGCAAAGAGTTTCTCAGGGAAACT & 1543 \\
\hline SpliNPV & 64 & TCCCCATCGTGAACGATCAAGAAGTGATGGACGTG & 123 \\
\hline ACMNPV & 1544 & $\begin{array}{l}|||||||||||||||||||||||||||||||||||||||||||||||||||||||||||||| \mid) \\
\text { TGGACCCGTTTCATGGAAGACAGCTTCCCTATCGTGAACGACCAAGAAATTATGGACGTG }\end{array}$ & 1603 \\
\hline SpliNPV & 124 & GCTTT-AGATTTTTGGCGCA & 182 \\
\hline ACMNPV & 1604 & TTCCTAGTGATCAACATGAGACCCACTAGGCCCAACAGATG-TTTCAGATTCCTGGCGCA & 1662 \\
\hline SplinPV & 183 & CGTTCCCCACGACGTGATCCGCATCGTCGAACC & 242 \\
\hline ACMNPV & 1663 & 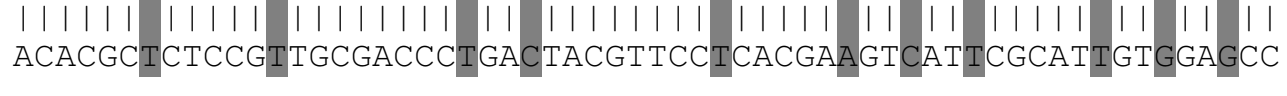 & 1722 \\
\hline SpliNPV & 243 & CCGCATCAGTCTCGCCAAGAAAGGTGGCGGCT & 301 \\
\hline ACMNPV & 1723 & ГACCGCATCAGCCTGGCCAAGAAGGGCGGCGGCT & 1781 \\
\hline SpliNPV & 302 & A-GAGTTTCATCGACA & 358 \\
\hline ACMNPV & 1782 & IACACGCACTCC-TTCGAAGAGTT-CATCAACC & 1838 \\
\hline SpliNPV & 359 & AGCCCATCGTCTAC & \\
\hline$A C M N P V$ & 1839 & $\mathrm{CCA}$ & \\
\hline
\end{tabular}

\section{Figure 3}

Comparison of Polh-cr nucleotide sequence (Acc\# $\underline{\text { AY442260) }}$ to its corresponding sequence of AcMNPV (Acc\# M25054) as a reference. Gaps and different nucleotides are shaded.

ith and Ramakrishnan [33] whereas $\mathrm{LC}_{50}$ was $4.677 \times 10^{6}$ $\mathrm{PIB} / \mathrm{ml}$ for 4-day old S. littoralis larvae. Similarly, Ashok and Ramakrishnan [34] reported higher $\mathrm{LC}_{50}\left(7.1 \times 10^{6}\right.$ $\mathrm{PIB} / \mathrm{ml}$ ) for 3-day old S. litura larvae. Also, Stiles and Himmerich [35] introduced higher $\mathrm{LC}_{50}$ of AcMNPV against $H$. zea $\left(3.46 \times 10^{4}-6.38 \times 10^{5} \mathrm{PIB} / \mathrm{ml}\right)$. Finally, Abdel-Aziz (personal communication) presented higher $\mathrm{LC}_{50} \mathrm{~s}(1.8 \times$ $10^{7}$ and $9.0 \times 10^{7} \mathrm{PIB} / \mathrm{ml}$, respectively) for $2^{\text {nd }}$ larval instar of $S$. littoralis. The variability of $\mathrm{LC}_{50} \mathrm{~s}$ is probably due to the method of surface treatment, homogeneously treated diet, feeding habit of the insect species [22] or due to difference in larval age $[36,37]$. It may also be due to difference in host susceptibility to NPV [4], number of virions per occlusion body, virulence of the virus strain and/or the difference in number of laboratory propagation cycles for the viral isolate. According to Van-Beek and Huges [38], the virulence of baculoviruses is best determined by the speed with which a given virus kills the insect pest.

LT values presented in Table (1) indicated that SpliNPV killed $2^{\text {nd }}$ instar larvae of $S$. littoralis one day faster than AcMNPV. In comparing our results with that presented by other authors, many considerations have to be taken into account. Host range and $\mathrm{LC}_{95} \mathrm{~s}$ of the viral isolates are the most important considerations. Although $\mathrm{LC}_{95}$ and $\mathrm{LT}_{95}$ that produced in this study are economically prohibitive, improving the insecticidal characteristics of such isolates (by formulation and synergistic additives) is a growing subject in many companies.

The full length of polyhedrin gene from lepidopteran NPVs ranged from 483 bp to 747 bp [39]. In case of polyhedrin gene from Spodoptera sp. NPVs, its full length ranges from $510 \mathrm{bp}$ to $747 \mathrm{bp}$ in comparison to that from Autographa sp. NPVs which ranges from 507 bp to $738 \mathrm{bp}$ [39]. Therefore, it could be said that Polh-cr represented about $65 \%$ of the full length of polyhedrin gene. On comparing nucleotide sequence of Polh-cr to all available sequences in the GenBank, it created a significant homology with $100 \mathrm{NPV}$ and $11 \mathrm{GV}$ genes. It showed 99\% identity with S. littoralis polyhedrin gene (Acc\# D01017), $95 \%$ with $S$. littura polyhedrin gene (Acc\# AY552474) and 93\% with S. littura polyhedrin genes (Acc\# AY549963, $\underline{\mathrm{AF} 325155}, \underline{\mathrm{AF} 037262}$ and $\underline{\mathrm{AF} 068189})$. In addition, it was 
SpliNPV ${ }_{\mathrm{a}}$ : V K P D T M K LI V N W N G K E F L R E T W T R F M E D S F P IV N D QE V M D V F L AcMNPV: V K P D T M K LV V N W S G K E F L R E T W T R F M E D S F P I V N D Q E I M D V F L SpliNPV 1 : V K P D T M K L I V N W N G K E FL R E T W T R F M E D F P IV N D Q E V M D V F L SpliNPV 2 : V K P D T M K L I V N W N G K E F L R ET W T R F M E D F P I V N D Q E V M D V F L

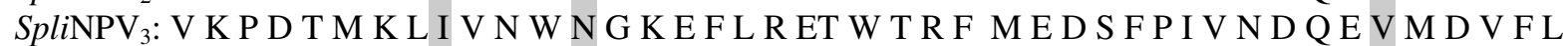
SpliNPV 4 : V K P D T M K L I V N W N G K E F L R ET W T R F M E D F P I V N D Q E V M D V F L

SpliNPV $:$ V V N M R P T R P N R C F R F L A Q H A L R C D PE Y V P H D V I R I V E PS Y V G T N AcMNPV: V I N M R P T R P N R C F R F L A Q H A L R C D P D Y V P H E V I R I V E P V Y V GN N SpliNPV $_{1}:$ V V N M R P T R P N R C FR F L A Q H A L R C D P E Y V P H D V I R I VE P S Y V G T N SpliNPV $_{2}$ : V V N M R P T R P N R C F R F L A Q H A L R C D P E Y V P H D V I R I VE P S Y V G T N SpliNPV $_{3}:$ V V N M R P T R P N R CFR F L A Q H A L R C D PE Y V P H D V IR I VEPS Y V G T N SpliNPV 4 : V V N M R P T R P N R C F R F L A Q H A L R C D P E Y V P H D V I R I V E P S Y V G T N

SpliNPV : N E Y R I S L A K K G G G C P V M N L H A E Y T T S F E S F I D K V I W Y N F Y K P I V Y I G T AcMNPV: NE Y R IS L A K K G G G C P V M N L H S E Y TH S FE E F INR V I W E N F Y K P I V Y V G T SpliNPV ${ }_{1}$ : NE Y R I S L A K K G G G C PV M N L H A E Y T T S F E S F I D K V I W Y N F Y K P I V Y V GT SpliNPV 2 : N E Y R I S L A K K G G G C PV M N L H A E Y T T S F E S F I D K V I W Y N F Y K P I V Y V G T

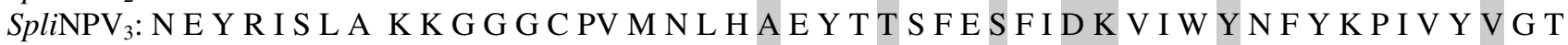
SpliNPV $_{4}$ : N E Y R I S L A K K G G G C P V M N L H A E Y T T S F E S F I D K V I W Y N F Y K P I V Y V G T

\section{Figure 4}

Comparison of amino acid sequence of the putative polypeptide of Polh-cr (Acc\# AAR04375) to its corresponding sequences of AcMNPV (Acc\# AAA46736) and other 4 SpliNPVs (Acc\# AAW49208, BAA00824, AATI0182 and AAW49207, respectively). The different amino acids were bolded and shaded using AcMNPV as a reference.

90\% similar to Lymantria dispar polyhedrin genes (Acc\# $\underline{\mathrm{AF} 499687}, \underline{\mathrm{AF} 081810}$ and $\underline{\mathrm{M} 23176}), 88 \%$ to Malacosoma neustria polyhedrin gene (Acc\# $\underline{\mathrm{X} 55658}$ ) and $87 \%$ to $B$. mori polyhedrin genes (Acc\# $\underline{M 10043}$ and X63614). Furthermore, it showed $86 \%$ homology with S. litura and Amsacta albistriga polyhedrin genes (Acc\# X94437 and AF118850, respectively) and 85\% with S. exigua and Malacosoma neustria polyhedrin gene (Acc\# AF169823; $\underline{\text { AY127899 }}$ and AJ277555, respectively). These results ensured that Polh-cr is a highly conserved region within polyhedrin gene of about one sixth of the known NPV species. Consequently, it could be used in many molecular techniques concerned with baculoviruses.

Knowing that the full length of polyhedrin protein from lepidopteran NPVs ranges from 161 a.a. (e.g. Hyphanteria cunea NPV, Acc\# AAW49190 and Bombyx mori, Acc\# $\underline{\mathrm{ABB} 16300}$ ) to 249 a.a. (e.g. Spodoptera litura NPVs, Acc\# $\underline{\mathrm{AAZ78353}}, \mathrm{NP} 258269$ and AAS90121). In case of Spodoptera $s p$. NPV, full length of polyhedrin protein ranges from 170 a.a. (Acc\# AAW49204) to 249 a.a. (Acc\# AAZ78353) in comparison to Autographa sp. NPV which ranges from 169 a.a. (Acc\# AAW63393) to 246 a.a. (Acc\# AAA46736). The deduced amino acid sequence of Polh- $\mathrm{cr}$ was compared to other polyhedrins. Alignment results revealed that Polh-cr was $100 \%$ and $99 \%$ identical to S. lit- toralis polyhedrins (Acc\# AAC33752, AAR04375; P24646, $\mathrm{UU0382}$ and BAA00824, respectively). It was also $99 \%$ similar to $S$. litura polyhedrins (Acc\# NP258269, $\underline{\mathrm{AAC} 09246}, \underline{\mathrm{AAL} 01689}$ and $\underline{\mathrm{AAS} 58468})$. In addition, it has $98 \%$ identity with polyhedrin of $S$. littoralis (Acc\# AA590121). Furthermore, it showed 89\% similarity with polyhedrins of $S$. exigua and Ecotropis obligua polyhedrins (Acc\# $\underline{\text { AAF33532, LQ1868, NP037761， }}$ 001586; $\underline{\mathrm{AAB} 53632}, \underline{\mathrm{AAQ} 88174}, \underline{\mathrm{P} 07388}$ and $\underline{\mathrm{AAA} 46739})$.

Using AcMNPV nucleotide sequence (Acc\# M25054) and amino acid sequence (Acc\# AAA46736) as references for comparison with our sequences, it was found that 57 different nucleotides and 12 gaps in nucleotide sequence resulted in 15 different amino acids in the putative polypeptide (I, N, V, V, E, D, S, T, A, T, S, D, K, Y and I a.a. from our putative polypeptide were replaced with $\mathrm{V}, \mathrm{S}, \mathrm{I}$, I, D, E, V, N, S, H, E, N, R, E and V a.a. from AcMNPV putative polypeptide, respectively). Surprisingly, Polh-cr putative polypeptide was identical to SpliNPV polypeptides (Acc\# AAW49208, BAA00824, AAW49207) with one amino acid replacement (I with $\mathrm{V}$ at the position 133). These results suggested the possible difference in codon usage among the compared isolates. It might also give a specific property to our putative polypeptide. 


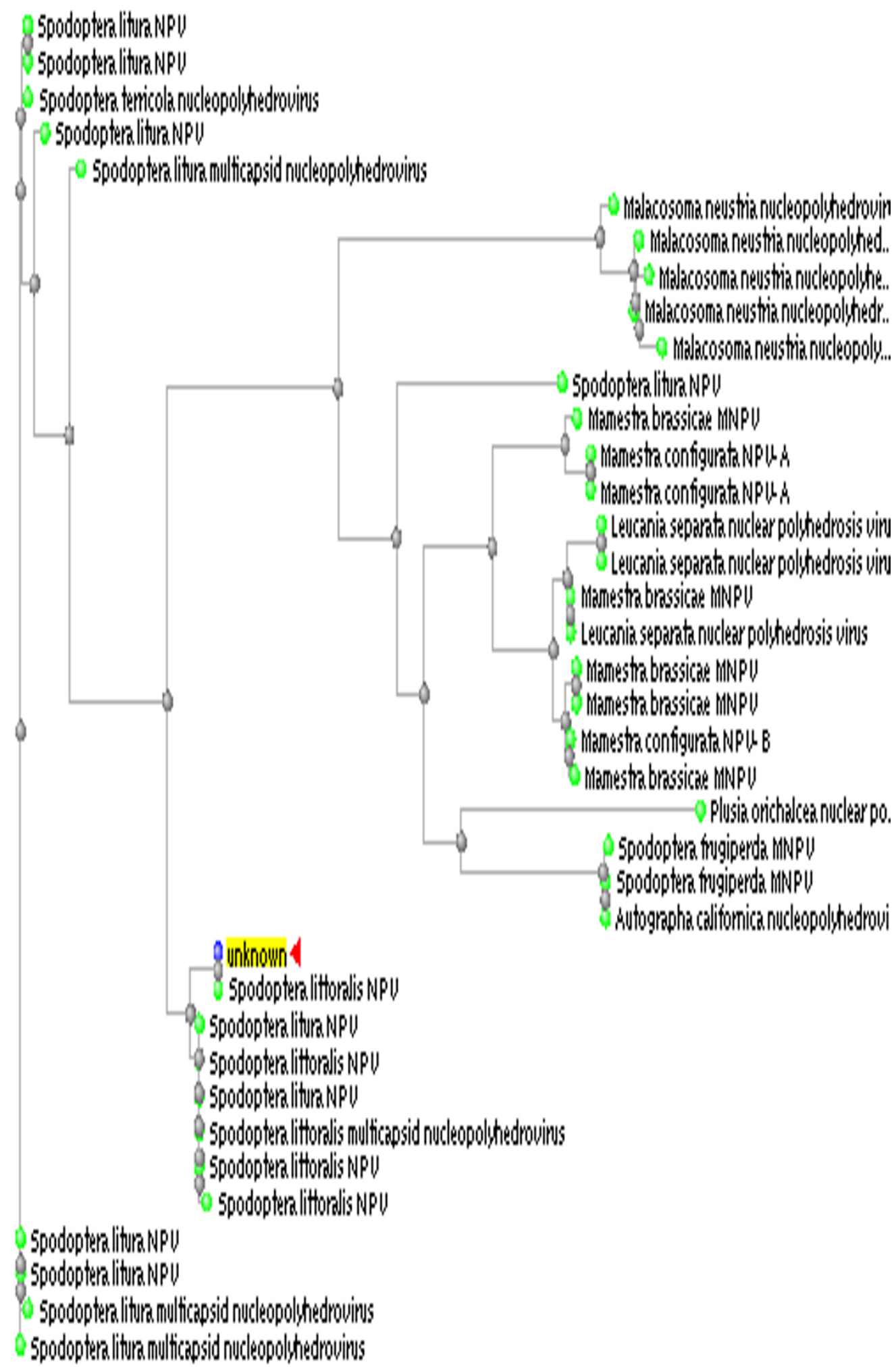

Figure 5

Phylogenetic analysis of Polh-cr nucleotide sequence compared to 38 published sequences. Unrooted tree was generated using ClustalW computer software. Full virus names are included in the tree. 


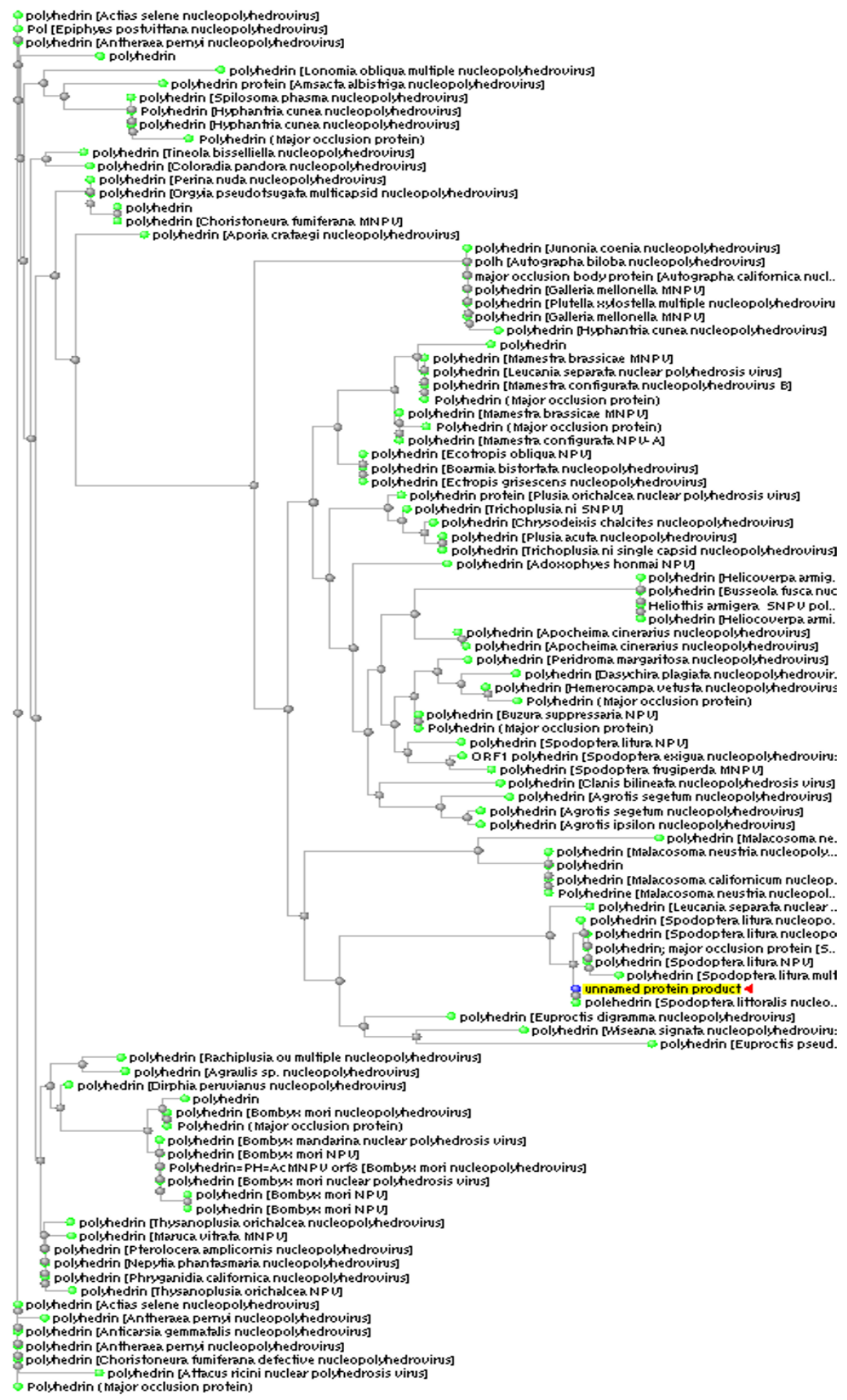

Figure 6

Phylogenetic analysis of Polh-cr deduced amino acid sequence compared to 102 published sequences. Unrooted tree was generated using ClustalW computer software. Full virus names are included in the tree. 
Phylogenetic analyses of the Polh-cr nucleotide seuquence and its deduced polypeptide revealed that Polh-cr is genetically related to a large number of published nucleotide sequences and to a larger number of published amino acid sequences. This finding made it is preferred to develop kits that use viral protein (polyhedrin) in detecting NPVs because it will be wider-used than DNA method.

\section{Conclusion}

In this paper, we described the cloning and sequencing of a highly conserved region in polyhedrin gene and the insecticidal activity of an Egyptian NPV isolate. To our knowledge, this is the first report that determines the sequence of this conserved region in an Egyptian isolate. Further studies to develop kits for ELISA, Western and dot blotting, hybridization as well as potential biocontrol agent are switched on. The availability of Polh-cr products would be helpful in studies concerning ELISA, PCR and other related molecular techniques. In addition, it provides a candidate for effective, sensitive and reproducible diagnostic tools for screening insects or/and other arthropods, especially crustacean species, crabs and shrimps for baculovirus infections and may be important in controlling (preventing/enhancing) baculovirus infection. Also, it may be useful in monitoring the distribution of NPVs, the fate of genes and release of wild type as well as genetically engineered NPVs. Furthermore, it will facilitate risk assessment, ecological and viral epidemiological studies.

\section{Competing interests}

The author(s) declare that they have no competing interests.

\section{References}

I. Martignoni ME, Iwai PJ: A catalog of viral diseases of Insects, Mites and Ticks. 4th edition. Portland, oregon: USDA Forest Service PNW-195; 1986.

2. Huber J: Use of baculoviruses in pest management programs. In "The biology of baculoviruses" Volume 2. Edited by: Granados RR, Federici B. CRC Press, Boca Raton, FL; 1986:181-202.

3. Wood HA, Granados RR: Genetically engineered baculoviruses as agents for pest control. Annu Rev Microbiol I99I, 45:69-87.

4. El-Salamouny S, Lange M, Jutzi M, Huber J, Jehle JA: Comparative study on the susceptibility of cutworms (Lepidoptera: Noctuidae) to Agrotis segetum nucleopolyhedrovirus and Agrotis ipsilon nucleopolyhedrovirus. J Invertebr Pathol 2003, 84:75-82.

5. Wood HA: Genetically enhanced baculovirus insecticides. In "Molecular biology of the biological control of pest and diseases of plants" Edited by: Gunasekaran M, Weber DJ. CRC Press, Boca Raton; 1996:91-104.

6. Couch JA: Free and occluded virus, similar to baculovirus, in hepatopancreas of pink Shrimp. Nature (London) 1974, 247:229-23I.

7. Hsu YL, Wang $\mathrm{KH}$, Yang YH, Tung MC, $\mathrm{Hu} C H$, Lo CF, Wang $\mathrm{CH}$, Hsu T: Diagnosis of penaeus monodon-type baculovirus by PCR and by ELISA of occlusion bodies. Dis Aquat Organ 2000, 40(2):93-99.

8. Marks H, Ren X, Witteveldt J, Sandbrink H, Vlak JM, van Hulten MCW: Transcription regulation and genomics of White Spot Syndrome Virus. In Diseases in Asian Aquaculture $V$ Edited by: Walker P, Lester R, Bondad-Reantaso MG. Fish Health Section, Asian Fisheries Society, Manila; 2005:363-377.
9. Halder M, Ahne W, Thomsen I: Detection of a baculovirus in the tiger prawn Penaeus monodon. Zentralbl Veterinarmed (B) 1989 , 36(4):257-260.

10. Chang PS, Lo CF, Kou GH, Lu CC, Chen SN: Purification and amplification of DNA from Penaeus monodon-type baculovirus (MBV). J Invertebr Pathol 1993, 62(2): I | 6- I20.

II. Poulos BT, Mary J, Bonami JR, Redman R, Lightner DV: Use of nonradioactively labeled DNA probes for the detection of a baculovirus from Penaeus monodon by in situ hybridization of fixed tissue. J Virol Methods 1994, 49(2): 187-193.

12. Faktor O, Raviv $D$ : A polymerase chain reaction for the detection of nucleopolyhedroviruses in infected insects: the fate of the Spodoptera littoralis virus in Locusta migratoria. J Virol Methods 1996, 61:95-101.

13. Belcher CR, Young PR: Colourimetric PCR-based detection of monodon baculovirus in whole Penaeus monodon postlarvae. J Virol Methods 1998, 74(I):2I-29.

14. Wang $\mathrm{CH}$, Yang HN, Liu HC, Kou GH, Lo CF: Nested polymerase chain reaction and in situ hybridization for detection of nucleopolyhedrosis. J Virol Methods 2000, 84:65-75.

15. Christian PD, Gibb N, Kasprzak AB, Richards A: A rapid method for the identification and differentiation of Helicoverpa nucleopolyhedroviruses (NPV Baculoviridae) isolated from the environment. J Virol Methods 200I, 96:5I-65.

16. de Moraes RR, Maruniak JE: Detection and identification of multiple baculoviruses using the polymerase chain reaction (PCR) and restriction endonuclease analysis. Mol Cells 200I, I I:334-40.

17. Ebling PM, Smith PA, van Frankenhuyzen K: DNA hybridization assay for detection of nucleopolyhedrovirus in whitemarked tussock moth (Orgyia leucostigma) larvae. Pest Manag Sci 200I, 57:66-7I.

18. Woo SD: Rapid detection of multiple nucleopolyhedroviruses using polymerase chain reaction. Mol Cells 200 I, I I:334-40.

19. Murillo R, Munoz D, Williams T, Mugeta N, Caballero P: Application of the PCR-RFLP method for the rapid differentiation of Spodoptera exigua nucleopolyhedrovirus genotypes. J Virol Methods 2006, I35:I-8.

20. El-Defrawi ME, Tappozada A, Mansour N, Zeid M: Toxicological studies on Egyptian cotton leaf worm Prodenia litura (F.) I: susceptibility of different larval instars of Prodenia litura to insecticides. J Econ Entomol 1964, 57:591-593.

21. Levinson $\mathrm{ZH}, \mathrm{Navon} \mathrm{A}$ : Ascorbic acid and unsaturated fatty acids in the nutrition of the Egyptian cotton leaf worm. J Insect Physiol 1969, 15:591-595.

22. Lacey LA, Vail PV, Hoffmann DF: Comparative activity of baculoviruses against the codling moth Cydia pomonella and three other tortricid pests of tree fruit. J Invertebr Pathol 2002, 80:64-68.

23. Abbott WS: A method of computing the effectiveness of an insecticide. J Econ Entomol 1925, 1 8:265-267.

24. Throne JE, Weaver DK, Chew V, Baker JE: Probit analysis of correlated data: multiple observations over time at one concentration. J Econ Entomol 1995, 88:1510-15I2.

25. Saiki RK, Gelfand DH, Stoffel S, Scharf SJ, Higuchi R, Horn GT, Mullis $\mathrm{KB}$, Erlich HA: Primer-directed enzymatic amplification of DNA with a thermostable DNA polymerase. Science 1988 , 239:487-49I.

26. Abdel-Hamid I, Salama MS, Madkour MA: The use of universal nested polymerase chain reaction (UN-PCR) to detect insect nuclear polyhedrosis viruses. J Egypt Ger Soc Zool 1996, 20(E):97-107.

27. Volkman LE, Blissard GW, Friesen P, Keddie BA, Possee R, Theilmann DA: Family baculoviridae. In "Virus taxonomy: Classification and nomenclature of viruses. Sixth report of the International committee on taxonomy of viruses" Volume 10. Edited by: Murphy FA, Fauquet CM, Bishop DHL, Ghabrial SA, Jarvis AW, Martelli GP, Mayo MA, Summers MD. Springer-Verlag, Vienna; 1995: 104-II3.

28. Abul-Nasr S: Further tests on the use of a polyhedrosis virus in the control of the cotton leaf worm Prodenia litura (F.). Insect Pathol 1959, I: I I2- I 20.

29. Cherry CL, Summers MD: Genotypic variation among wild isolates of two nuclear polyhedrosis viruses isolated from Spodoptera littoralis. J Invertebr Pathol 1985, 46:289-295. 
30. Klein M, Podoler H: Studies on the application of a nuclear polyhedrosis virus to control population of the Egyptian Cotton worm, Spodoptra littoralis. J Invertebr Pathol 1978, 32:244-248.

31. Abot AR, Moscardi F, Fuxa JR, Sosa-Gomez DR, Richter AR: Susceptibility of populations of Anticarsia gemmatalis (Lepidoptera: Noctuidae) from Brazil and the United States to a nuclear polyhedroses virus. J Entomol Sci 1995, 30(I):62-69.

32. Pawar VM, Ramakrishnan N: Investigation of the nuclear polyhedrosis virus of Spodoptera litura (Fab). III. Bioassay of virus activity. Indian J Entomol 1975, 37:374-376.

33. Komolpith $U$, Ramakrishnan N: Bioassay of the nuclear polyhedrosis virus against larval stages of Spodoptera litura (Fab) and the effect of protectants against ultraviolet light. Proc Indian Acad Sci 1975, 83: 195-203.

34. Ashok MV, Ramakrishnan N: Certain observations on the physico-chemical properties of nuclear polyhedrosis virus of Spodoptera littoralis (Fabricius). J Entomol Res 198I, 5(I):43-46.

35. Stiles B, Himmerich S: Autographa californica NPV isolates: Restriction endonuclease analysis and comparative biological activity. J Invertebr Pathol 1998, 72:174-177.

36. Payne CC, Tatchell GM, Williams CF: The comparative susceptibilities of Pieris brassicae and Pieris rapae to a granulosis virus from Pieris brassicae. J Invertebr Pathol 198I, 38:273-280.

37. Payne CC: Insect viruses as control agents. Parasitol 1982 84:35-77.

38. Van-Beek NA, Hughes PR: The response time of insect larvae infected with recombinant bacuoloviuses. I Invertebr Pathol 1998, 72:338-347.

39. Jehle JA, Lange M, Wang H, Hu Z, Wang Y, Hauschild R: Molecular identification and phylogenetic analysis of baculoviruses from Lepidoptera. Virology 2006, 346(I): I80-193.

Publish with Bio Med Central and every scientist can read your work free of charge

"BioMed Central will be the most significant development for disseminating the results of biomedical research in our lifetime. "

Sir Paul Nurse, Cancer Research UK

Your research papers will be:

- available free of charge to the entire biomedical community

- peer reviewed and published immediately upon acceptance

- cited in PubMed and archived on PubMed Central

- yours - you keep the copyright

Submit your manuscript here:

http://www.biomedcentral.com/info/publishing_adv.asp
BioMedcentral 